\title{
AVALIAÇÃO AGRONÔMICA DE LINHAGENS E HÍBRIDOS DE MAMOEIRO ${ }^{1}$
}

\author{
JORGE LUIZ LOYOLA DANTAS ${ }^{2}$, RANGEL SALES LUCENA ${ }^{3}$, \\ SANDIELLE ARAÚJO VILAS BOAS ${ }^{4}$
}

RESUMO - Objetivou-se avaliar o potencial agronômico de híbridos e linhagens de mamoeiros sintetizados pela Embrapa Mandioca e Fruticultura, visando a identificar e a selecionar genótipos com boas características agronômicas, passíveis de exploração no programa de melhoramento genético e uso direto no sistema de produção de mamão. O trabalho foi conduzido em área do Setor de Campos Experimentais da Embrapa Mandioca e Fruticultura, em Cruz das Almas - BA. Foram avaliados 22 genótipos (oito linhagens, doze híbridos e duas testemunhas: Sunrise Solo e Tainung $\mathrm{n}^{\mathrm{o}}$ 1) em delineamento de blocos casualizados, com quatro repetições, contendo seis plantas por parcela, totalizando 528 plantas no ensaio. Para a maioria dos caracteres, observaram-se diferenças significativas a $1 \%$ e $5 \%$ de probabilidade, exceto para diâmetro do caule (DC). A linhagem L60 e o híbrido H10.60 destacaram-se com as menores médias para a altura da planta (AP) e a altura de inserção dos primeiros frutos (AIPF), e não diferiram estatisticamente entre si. As linhagens L10 e L72, e os híbridos H10.26, H10.60 e H10.72 apresentaram maiores médias de números de frutos comerciais (NFC) que a testemunha Sunrise Solo. Para produtividade (PROD), observou-se ampla variabilidade entre os tratamentos, sendo que $75 \%$ dos híbridos e linhagens superaram as testemunhas. Mais de 50\% dos genótipos apresentaram médias de sólidos solúveis (SS) superiores a $12^{\circ}$ Brix. Com o objetivo de reunir características favoráveis para o desenvolvimento de novas variedades, as linhagens e os híbridos que apresentaram comportamentos satisfatórios para os principais caracteres foram: L60 e H10.60, para AIPF e AP; L10, L72, H10.26, H10.60 e H10.72, para NFC; L10, H10.72, H26.72, H33.56 e H36.45 para PROD; e L26, L36, H10.26, H10.60 e H60.72, para SS.

Termos para indexação: Carica papaya L., melhoramento genético, qualidade de frutos.

\section{AGRONOMIC EVALUATION OF PAPAYA LINES AND HYBRIDS}

ABSTRACT - This study aimed to evaluate the agronomic potential of papaya hybrids synthesized by Embrapa Cassava \& Fruits, to identify and select genotypes with good agronomic characteristics, exploitable in the breeding program and direct use in the papaya production system. This study was carried out in the Experimental Field Sector of Embrapa Cassava \& Fruits, Cruz das Almas - BA. It was evaluated 22 genotypes (eight lines, twelve hybrids and two witnesses: Sunrise Solo and Tainung $n^{\circ} 1$ ) in a randomized block design with four replications of six plants per plot, totalizing 528 plants. For most characters significant differences were observed at 1\% and 5\% probability, except for stem diameter (SD). The line L60 and H10.60 stood out with the lowest averages for plant height (PH) and insertion height of the first fruits (IHFF), and were not statistically different. Lines L10 and L72, and the hybrids H10.26, H10.60 and H10.72 showed higher averages of numbers of commercial fruits (NCF) than the witness Sunrise Solo. For yield, it was observed wide variability among treatments, with $75 \%$ of lines and hybrids overcame the witnesses. Over $50 \%$ of the genotypes showed soluble solids (SS) averages above $12^{\circ}$ Brix. Aiming to associate favorable characteristics for development of new varieties, lines and hybrids that showed satisfactory behavior to the main characters were: L60 and H10.60 to IHFF and PH; L10, L72, H10.26, H10.60 and H10.72, for NCF; L10, H10.72, H26.72, H33.56 and H36.45, for productivity (PROD), and L26, L36, H10.26, H10.60 and H60.72, for SS. Index terms: Carica papaya L., improvement, fruit quality.

\footnotetext{
'(Trabalho 022-14). Recebido em: 16-01-2014. Aceito para publicação em: 30-10-2014.

${ }^{2}$ Dr. Pesquisador da Embrapa Mandioca e Fruticultura, Rua da Embrapa, s/nº, Caixa Postal 007, 44380-000, Cruz das Almas - BA. E-mail: jorge.loyola@embrapa.br

${ }^{3}$ Eng $^{\circ}$. Agro ${ }^{\circ}$, Mestre em Recursos Genéticos Vegetais. Universidade Federal do Recôncavo da Bahia, Campus Universitário de Cruz das Almas, 44380-000, Cruz das Almas - BA. E-mail: rangel_lucena@yahoo.com.br

${ }^{4} \mathrm{Eng}^{\mathrm{a}}$. Agr ${ }^{\mathrm{a}}$., Mestranda em Ciências Agrárias. Universidade Federal do Recôncavo da Bahia, Campus Universitário de Cruz das Almas, 44380-000, Cruz das Almas - BA. E-mail: sandyvilasboas@hotmail.com
} 


\section{INTRODUÇÃO}

O mamoeiro (Carica papaya L.) é a única espécie representante do gênero Carica, amplamente distribuído pela América tropical e que apresenta frutos de interesse comercial (BADILLO, 2000). O Brasil é um dos principais produtores de mamão no cenário internacional, com produção anual de 1,87 milhão de toneladas, que representa $16,67 \%$ do volume global (FAO, 2012). A área colhida está em torno de 34.379 hectares, merecendo destaque os Estados da Bahia, Espírito Santo, Ceará e Rio Grande do Norte, que são responsáveis por cerca de $92 \%$ da produção nacional (IBGE, 2011).

Apesar da importância da cultura, atualmente ainda há pouca disponibilidade de cultivares, tornando o cultivo do mamoeiro vulnerável a fatores bióticos e abióticos, como ataque de pragas e doenças, variações climáticas, estresse hídrico, estresse salino, entre outros. Assim, a caracterização e a exploração da variabilidade genética existente no gênero Carica pode revelar recursos genéticos de grande valor, que podem contribuir para o desenvolvimento de novas variedades para o aumento da competitividade e da sustentabilidade no sistema de produção da cultura (DANTAS; LIMA, 2001).

Bancos de germoplasma são excelentes fontes de recursos genéticos e assumem importância fundamental no que se refere à variabilidade genética necessária para subsidiar o melhoramento de plantas para obtenção de genótipos superiores com distintas constituições gênicas (GEPTS, 2006).

Em 1995, a Embrapa Mandioca e Fruticultura iniciou a autofecundação de alguns acessos disponíveis em seu Banco Ativo de Germoplasma de Mamão - BAG-Mamão, objetivando a formação de um banco de linhagens. Foram então obtidas seis linhagens do grupo Solo e outras seis do grupo Formosa, após cinco a oito gerações de autofecundação, as quais foram utilizadas em cruzamentos dialélicos visando à síntese de híbridos, para diminuir a dependência de importação de sementes, que onera o custo de produção de mamão.

$\mathrm{O}$ melhoramento genético pode contribuir efetivamente para aumentar a disponibilidade de híbridos no mercado nacional, com menor custo de aquisição de sementes, maior produtividade, melhoria na qualidade e no aspecto do mamão, permitindo a obtenção de um produto final de melhor qualidade, com características físico-químicas e sensoriais superiores, com redução dos custos de produção e garantia de maior competitividade (DANTAS;OLIVEIRA, 2009). Assim sendo, o presente trabalho teve como objetivo realizar a avaliação agronômica e de qualidade de frutos de linhagens e híbridos de mamoeiro do programa de melhoramento genético da Embrapa Mandioca e Fruticultura, visando a identificar e a selecionar pelo menos um híbrido com características agronômicas superiores aos das variedades comerciais existentes.

\section{MATERIAL E MÉTODOS}

\section{Etapa 1 - Estabelecimento de campo de cruzamentos para síntese de híbridos}

No ano agrícola de 2010/2011, foi instalado um campo de cruzamentos para síntese de novos híbridos e avaliação agronômica preliminar de oito linhagens de mamoeiro em área do Setor de Campos Experimentais da Embrapa Mandioca e Fruticultura, em Cruz das Almas - BA, utilizando como testemunhas 'Sunrise Solo', 'Tainung n ${ }^{\circ}$ ' e 'Vigilante'. O delineamento utilizado foi o de blocos casualizados, com quatro repetições, sendo a parcela constituída por cinco plantas.

No ensaio, foi dada ênfase à síntese de híbridos segundo o dialelo completo, sem recíprocos, utilizando o método 2, modelo B, definido por Griffing (1956), para os cruzamentos entre as linhagens Solo x Solo e Formosa x Formosa, realizando os cruzamentos conforme disposto nas Tabelas 1 e 2, respectivamente. As autofecundações dos genitores (linhagens) foram realizadas concomitantemente aos cruzamentos para a obtenção dos híbridos.

Após a realização dos cruzamentos e das autofecundações, esperou-se um período de 4 a 5 meses para colher os frutos, em estádio de maturação 1. As sementes foram extraídas de frutos totalmente maduros (estádio de maturação 5), lavadas em água corrente, com remoção da sarcotesta e secas à sombra durante o período de 72 horas. Em seguida, foram acondicionadas em recipientes de papel, devidamente identificados, e armazenadas em câmara fria à temperatura de $10^{\circ} \mathrm{C}$.

Etapa 2 - Avaliação de linhagens e híbridos

Este experimento foi realizado em área do Setor de Campos Experimentais da Embrapa Mandioca e Fruticultura, em Cruz das Almas-BA. A cidade está situada a $12^{\circ} 40^{\prime} 39^{\prime \prime}$ de latitude S e 3906'22" de longitude O de Greenwich, a 226 m de altitude. O clima da região é do tipo subúmido, com temperatura média de $24,1^{\circ} \mathrm{C}$, umidade relativa de $86 \%$ e pluviosidade média anual de $1.400 \mathrm{~mm}$, com períodos de chuvas entre os meses de março e agosto (INMET, 2014). O solo é classificado como Latossolo Vermelho-Amarelo, de textura argilosa e declividade de $0 \%$ a 3\% (EMBRAPA, 2006). 
Foram avaliados 22 genótipos de mamoeiro, sendo 8 linhagens [4 do grupo Solo (L26; L60 e L72 - peso médio dos frutos inferior a $750 \mathrm{~g}$; L10 - Solo alongado, com peso médio dos frutos semelhante ao de linhagem do grupo Formosa) e 4 do grupo Formosa (peso médio dos frutos superior a $750 \mathrm{~g}$ )], 12 híbridos e duas testemunhas ('Sunrise Solo' e o híbrido 'Tainung $\mathrm{n}^{\circ} 1$ '), em delineamento de blocos casualizados, com quatros repetições, contendo seis plantas por parcela, totalizando 528 plantas no ensaio.

As sementes dos 22 genótipos (híbridos, linhagens e testemunhas) foram submetidas à germinação em sacos de polietileno, contendo substrato comercial Plantmax ${ }^{\circledR}$. Utilizou-se de 80 sacos de polietileno para cada genótipo, e a metodologia adotada para a semeadura foi de 3 sementes por saco. Nos casos em que as três sementes germinaram, foi efetuado o desbaste, deixando-se apenas uma muda por saco, eliminando-se as mudas excedentes ou efetuando-se o transplantio para os sacos onde não houve germinação de sementes.

As mudas foram plantadas em campo, com aproximadamente $20 \mathrm{~cm}$ de altura, sendo plantadas três mudas por cova, para assegurar a presença de, pelo menos, uma planta hermafrodita por cova. $\mathrm{O}$ plantio foi realizado em área com irrigação localizada, com microaspersores, utilizando espaçamento de 3,0 $\mathrm{m}$ entre linhas e $1,8 \mathrm{~m}$ entre plantas. As demais práticas culturais e os tratos fitossanitários foram aqueles preconizados para a cultura (MARTINS; COSTA, 2003).

As avaliações dos genótipos foram efetuadas durante todo o ciclo de produção da cultura, embora a colheita dos frutos para as análises de qualidade tenha sido concentrada do oitavo ao décimo segundo mês após o plantio. Utilizou-se de 16 descritores quantitativos do Manual de Descritores para Mamão [Catálogo de Germoplasma de Mamão (Carica papaya L.)], adaptado pela Embrapa Mandioca e Fruticultura a partir dos descritores inicialmente estabelecidos pelo International Board for Plant Genetic Resources (IBPGR, 1988), atualmente Bioversity International, com algumas alterações sugeridas por Dantas et al. (2000). Os principais caracteres morfoagronômicos e referentes à qualidade de frutos avaliados foram: altura da planta (AP), em cm; altura de inserção dos primeiros frutos (AIPF), $\mathrm{cm}$; diâmetro do caule (DC): cm; precocidade, avaliada mediante indicação da data da primeira colheita de frutos; número de frutos comerciais por planta (NFC); número de frutos deformados por planta (NFD); número de nós sem frutos (NNSF); produtividade (PROD): expressa em t.ha-1, estimada pela multiplicação do número de frutos comercias por planta (NFC), pelo peso médio do fruto por planta; comprimento de fruto $(\mathrm{CF}), \mathrm{cm}$; diâmetro de fruto (DF), cm; peso de fruto (PF), gramas; sólidos solúveis (SS): $\mathrm{em}^{\circ}$ Brix, com auxílio de refratômetro digital portátil modelo $r^{2}$ mini Reichert; firmeza do fruto (FF), em $\mathrm{kg} / \mathrm{cm}^{2}$; firmeza da polpa (FP), expressa em $\mathrm{kg} / \mathrm{cm}^{2}$; diâmetro da cavidade interna do fruto (DCI), cm; espessura da polpa (EP), cm; acidez titulável (AT), em \% de ácido cítrico, por titulação com $\mathrm{NaOH} 0,1 \mathrm{~N}$ e pH.

As mensurações dos caracteres morfoagronômicos e de qualidade de frutos foram realizadas em todas as seis plantas que compõem a parcela, para todos os genótipos; entretanto, para análise de qualidade de frutos avaliou-se um fruto por planta, totalizando 6 frutos por parcela e 24 frutos para cada tratamento.

Os dados obtidos foram submetidos à análise de variância, de acordo com o modelo: $Y_{i j}=m+$ $t_{i}+b_{j}+e_{j}$, em que: $Y_{i j}$ é o valor da característica para a $i$-ésima testemunha no $j$-ésimo bloco; $m$ é a média geral do experimento; $t_{i}$ é o efeito do $i$-ésimo tratamento, que pode ser decomposto em $T_{i}=$ efeito da $i$-ésima testemunha, $\operatorname{com} i=1,2, \ldots$. t e $G_{i}^{j}=$ efeito do $i$-ésimo genótipo, $\operatorname{com} i=1,2, \ldots . g_{j} ; b_{j}$ é o efeito do $j$-ésimo bloco; $e_{i j}$ é o erro aleatório. Em seguida, realizou-se a comparação das médias dos genótipos pelo teste de Skott-Knott, a 5\% de probabilidade. Todas as análises estatísticas foram realizadas com auxílio do Programa Genes (CRUZ, 2006).

\section{RESULTADOS E DISCUSSÃO}

A maioria dos caracteres agronômicos e referentes à qualidade de frutos apresentou diferenças significativas a $1 \%$ de probabilidade, pelo teste $\mathrm{F}$ (Tabela 3), com resultados significativos a 5\% de probabilidade para os caracteres número de nós sem frutos (NNSF) e diâmetro de fruto (DF). Por outro lado, não houve diferença significativa entre os tratamentos para diâmetro do caule (DC). Esses resultados indicam ampla variabilidade genética para os caracteres avaliados entre os genótipos em estudo, passível de seleção de linhagens e/ou híbridos com características agronômicas desejáveis pelo consumidor, para uso direto no sistema de produção do mamoeiro.

Os coeficientes de variação ( CVs) apresentaram valores oscilando de 1,28\% a 37,93\%. Os caracteres AP, CF, EP, SS e pH exibiram CVs abaixo de $10 \%$, demonstrando pouca influência do ambiente. $\mathrm{O}$ intervalo de coeficiente de variação de 10 a $20 \%$ abrangeu 07 caracteres (APF, DC, NFC, 
DF, PF, DCI e AT), enquanto os caracteres NFD, NNSF, PROD, FF e FP apresentaram CVs superiores a $20 \%$. Esses resultados corroboram os dados obtidos por Oliveira et al. (2010), que observaram coeficientes de variação variando de 10,38 a $42,62 \%$ para as características sólidos solúveis, altura da planta, diâmetro do caule, firmeza do fruto, número de frutos, peso do fruto e acidez titulável. Apesar de alguns caracteres terem apresentado coeficientes de variação elevados $(\mathrm{FF}=30,02 \%$ e $\mathrm{FP}=37,93 \%)$, de maneira geral, o presente trabalho teve boa precisão experimental, e os altos valores obtidos devem-se ao fato de que as características avaliadas são de natureza poligênica e bastante influenciadas pelo ambiente.

$\mathrm{Na}$ Tabela 4, observam-se as médias dos genótipos para os caracteres agronômicos AIPF, AP, DC, NFC, NFD, NNSF e PROD de mamoeiro, comparadas pelo teste de Scott-Knott. Para a característica altura da planta (AP), houve formação de três grupos estatísticos. Os genótipos que mais se destacaram e não diferiram estatisticamente entre si foram a linhagem L60 $(108,13 \mathrm{~cm})$ e o híbrido H10.60 (125,17 cm). Estes dois genótipos apresentaram comportamento semelhante para AIPF, mostrando-se promissores no que tange à seleção de genótipos com menores alturas de frutos e de plantas. Valores relativamente superiores foram observados por Ferreira et al. (2012), com média de altura da planta igual a $2,79 \mathrm{~m}$.

A altura de inserção dos primeiros frutos apresentou média variando de 74,82 a $119,79 \mathrm{~cm}$. Marin et al. (1989) recomendam selecionar mamoeiro com altura de inserção inferior a $80 \mathrm{~cm}$. Com base nesta informação, a linhagem L60 e o híbrido H10.60 encaixam-se nesta recomendação, com valores médios de 79,82 e 74,84 cm, respectivamente. Apesar de o híbrido H10.26 apresentar média de $81,13 \mathrm{~cm}$, não diferiu estatisticamente da linhagem L60 e do híbrido H10.60. Estes três genótipos são pertencentes ao grupo Solo e, quando comparados com a testemunha Sunrise Solo $(119,79 \mathrm{~cm})$, observa-se que a altura dos primeiros frutos foi significativamente inferior. Esta característica é de fundamental importância nos programas de melhoramento de mamoeiro, pois quanto menor o valor obtido para este caráter, mais precocemente a planta começa a produzir frutos, indicando precocidade e maior facilidade para a colheita de frutos em ciclos de produção mais avançados.

Apesar de observar diferenças entre as médias dos tratamentos para diâmetro do caule, com amplitude de $1,73 \mathrm{~cm}$, não foi possível detectar diferenças significativas a 5\% entre genótipos, indicando restrita variabilidade genética para esta característica. Fraife Filho et al. (2001) e Silva et al. (2007) sugerem que a seleção de plantas de mamoeiro com maior diâmetro do caule pode resultar em plantas mais produtivas, em virtude da alta correlação genética entre essas características.

Observou-se ampla variabilidade entre os genótipos para NFC, com formação de quatro grupos estatísticos. As linhagens L10 e L72, e os híbridos H10.26, H10.60 e H10.72, todos pertencentes ao grupo Solo, foram os que apresentaram os maiores rendimentos para esta característica e não diferiram estatisticamente entre si, com valores médios de 36,53 a 42,61 números de frutos comerciais por planta. Dentre os genótipos do grupo Solo, as linhagens L10 e L72 se mostraram promissoras como genitores para produção de frutos comerciais, passível de maior exploração no programa de melhoramento para síntese de novos híbridos de mamoeiro, com destaque para a L10, que se constitui em parental de todos os híbridos que obtiveram as melhores médias (H10.26, H10.60 e H10.72). Já, entre os genótipos do grupo Formosa, a linhagem L33 destacou-se das demais, com valor médio de NFC igual a 29,83. A testemunha 'Tainung n ${ }^{\circ} 1$ ', que é um híbrido importado, obteve média igual a 14,84 , sendo superada por todos os híbridos e linhagens do grupo Formosa, cujas médias variaram de 17,09 a 31,46.

As características número de frutos deformados (NFD) e número de nós sem frutos (NNSF) são de fundamental importância para os programas de melhoramento, pois estão diretamente relacionadas à produtividade. Quanto maiores os valores de NFD e NNSF, consequentemente, menor vai ser a produtividade, indicando que a seleção de genótipos de mamoeiro deve ser realizada visando a selecionar aqueles que apresentam menores valores para NFD e NNSF. Assim, mais de 50\% dos genótipos avaliados apresentaram menores valores de NFD, e cerca de $36 \%$ dos genótipos obtiveram as menores médias para NNSF, demonstrando ampla variabilidade para estes caracteres. A média para NFD teve variação de 0,92 a 4,69, tendo a linhagem L60 e os híbridos H26.60 e H60.72 destacado-se por apresentarem médias inferiores à da testemunha Sunrise Solo $(1,46)$. No grupo Formosa, apenas a linhagem L56 e o híbrido H36.56 exibiram médias inferiores à do híbrido 'Tainung $\mathrm{n}^{\circ} 1$ '. Resultados semelhantes foram observados por Silva et al. (2008) que, ao trabalharem com 15 genótipos, obtiveram médias de 0,85 e 1,13 para número de frutos carpeloides e número de frutos deformados, respectivamente.

Para produtividade (PROD), houve a 
formação de três grupos. A linhagem L36 apresentou a menor média, igual a 29,19 t.ha ${ }^{-1}$, e a maior média foi observada para o híbrido H36.45 (80,81 t.ha $\left.{ }^{-1}\right)$. Detectou-se ampla variabilidade para esta característica, com amplitude total de 44,01 t.ha-1. Entre os materiais do grupo Solo, observa-se que $80 \%$ dos genótipos apresentaram médias maiores que a da testemunha Sunrise Solo $\left(31,25\right.$ t.ha $\left.^{-1}\right)$. De forma similar, foi observado entre os materiais do grupo Formosa que $70 \%$ dos genótipos superaram a testemunha 'Tainung $\mathrm{n}^{\circ} 1$ '.

A média nacional de produtividade da testemunha Sunrise Solo é igual a 40 t.ha ${ }^{-1}$. No presente trabalho, as linhagens L10 e L72, e todos os híbridos do grupo Solo apresentaram médias superiores a 40 t.ha $^{-1}$, demonstrando serem promissoras e passíveis de indicação futura no uso direto para o sistema de produção de mamão. Entre os materiais do grupo Formosa, apenas os híbridos H33.56 e H36.45 apresentaram resultados satisfatórios para produtividade, superando a média nacional da testemunha Tainung $\mathrm{n}^{\circ} 1\left(60\right.$ t.ha $\left.^{-1}\right)$, com destaque para o híbrido H36.45, obtendo média de 80,81 t.ha' ${ }^{-1}$.

Precocidade é um caráter de grande importância nos programas de melhoramento, pois normalmente está associada a portes baixos. Em mamão, o início de floração ocorre normalmente de 3 a 4 meses após o plantio, com início de produção de frutos dos 8 a 10 meses de plantio. Segundo Simão (1998), os caracteres altura dos primeiros frutos e precocidade são hereditários, portanto, transmissíveis. Assim, a linhagem L60 e os híbridos H10.26, H26.72 e H60.72 foram mais precoces que os demais genótipos, com início de colheita dos primeiros frutos variando de 237 a 239 dias após o plantio, superando as testemunhas Sunrise Solo e Tainung $\mathrm{n}^{\circ} 1$, que tiveram início de colheita aos 250 e 257 dias após o plantio, respectivamente.

As médias dos caracteres referentes à qualidade de frutos estão dispostas na Tabela 5. O comprimento e o diâmetro de frutos apresentaram variações da ordem de 13,5 a $25,1 \mathrm{~cm}$ e 8,6 a 11,5 $\mathrm{cm}$, e valores médios iguais a 19,22 e 9,94 cm, respectivamente. Os híbridos e linhagens do grupo Solo apresentaram comportamento semelhante para CF e DF, exceto a linhagem L10, que obteve média para $\mathrm{CF}$ fora do padrão recomendado para frutos do grupo Solo. A linhagem L60 apresentou comportamento muito próximo da testemunha Sunrise Solo para os caracteres CF, DF e PF, sendo que esta linhagem (L60) foi a que apresentou a menor média para altura da planta, indicando potencial agronômico para estas características.
Os genótipos do grupo Formosa apresentaram valores médios de CF e DF oscilando de 18,2 a 22,4 $\mathrm{cm}$ e 9,2 a 10,8 cm, respectivamente. A testemunha Tainung $\mathrm{n}^{\circ} 1$ diferiu estatisticamente dos demais genótipos e obteve a maior média para $\mathrm{CF}$, porém manteve comportamento similar aos outros genótipos para DF. Os híbridos H33.56, H36.45 e H45.56 mostraram-se promissores para os caracteres CF e DF, por apresentarem comportamentos semelhantes aos frutos da testemunha Tainung $n^{\circ} 1$. Souza et al. (2009), em seu trabalho com avaliação físicoquímica de frutos provenientes do híbrido Tainung $\mathrm{n}^{\circ} 1$, observaram médias de comprimento e diâmetro do fruto iguais a 20,97 e 10,64 cm, respectivamente.

O peso dos frutos de mamão faz parte de um conjunto de características cruciais na seleção de variedades. O mercado do Solo tem preferência por frutos com pesos variando de 300 a $650 \mathrm{~g}$, e o mercado do grupo Formosa exige frutos variando de 1.000 a $1.300 \mathrm{~g}$. Assim, três genótipos do grupo Solo atendem a essa exigência: as linhagens L26 e L60, e o híbrido H10.60, com médias de 554,3 g, 506,3 g e 624,3 g, respectivamente. Os padrões de classificação para esta característica são variáveis, e a escolha do peso ideal do fruto dependerá de seu formato para facilitar o processo de embalagem e transporte. Dessa forma, os genótipos L26, L60 e H10.60 tendem a ter calibre 15 a 18, que tem melhor aceitação no mercado do grupo Solo. A linhagem L56 e os híbridos H33.36 e H45.56, todos do grupo Formosa, tiveram médias entre 1.000 e $1.300 \mathrm{~g}$.

A espessura da polpa e o diâmetro da cavidade interna são características que estão diretamente associadas, pois quanto menor o diâmetro da cavidade interna, maior a espessura da polpa. Maior espessura da polpa irá condicionar maior rendimento de polpa, constituindo-se em atributo de grande interesse econômico, enquanto o diâmetro da cavidade interna é um caráter de fundamental importância para a comercialização e o transporte dos frutos. Todos os genótipos apresentaram valores médios para EP superiores a 2,0 cm, com média geral igual a 2,63 $\mathrm{cm}$. De acordo com Yamanishi et al. (2006), espessura média da polpa acima de 2,0 cm é considerada de valor ideal para comercialização. Concordando com esse resultado, Fioravanço et al. (1996) encontraram valores de espessura da polpa de 2,01 a 2,37 cm, e Silva et al. (2010) observaram média de $2,3 \mathrm{~cm}$.

Para o diâmetro da cavidade interna, houve a formação de dois grupos, com variação das médias de 3,90 a $6,01 \mathrm{~cm}$. O grupo das menores médias foi constituído por 7 genótipos, correspondendo a $31,81 \%$ do total. Todas as linhagens do grupo Solo 
tiveram as menores médias, passível de exploração em cruzamentos para obtenção de híbridos com menores valores de diâmetro da cavidade interna.

A firmeza do fruto (FF) é um caráter de fundamental importância no programa de melhoramento para a cultura do mamoeiro, influenciando diretamente na resistência do fruto contra choques mecânicos e garantindo-lhe maior longevidade em prateleiras.

Houve formação de dois grupos entre os genótipos para $\mathrm{FF}$, a menor média foi $1,4 \mathrm{~kg} / \mathrm{cm}^{2}$ e a maior $3,6 \mathrm{~kg} / \mathrm{cm}^{2}$. O grupo de genótipos que obtive as maiores médias foi constituído por quatro linhagens e sete híbridos que apresentaram valores variando de 2,4 a 3,6 kg/ $\mathrm{cm}^{2}$. A linhagem L10 e o híbrido H10.72 destacaram-se por apresentar médias de 3,6 e 3,5 kg/ $\mathrm{cm}^{2}$, respectivamente. Este pode ser um indicativo de que esta característica seja de alta herdabilidade pelo fato de a linhagem L10 ser um dos parentais do híbrido H10.72.

Já para a firmeza da polpa (FP), observouse ampla variabilidade entre os tratamentos, com variação da média de 0,3 a $2,1 \mathrm{~kg} / \mathrm{cm}^{2} e$ com formação de quatro grupos, sendo que a linhagem L10 diferiu estatisticamente das demais e obteve a maior média, igual a $2,1 \mathrm{~kg} / \mathrm{cm}^{2}$. Os híbridos H10.72 e $\mathrm{H} 60.72$ tiveram médias de 1,6 e $1,3 \mathrm{~kg} / \mathrm{cm}^{2}$, respectivamente. As testemunhas Sunrise Solo e Tainung $n^{\circ} 1$ ficaram no grupo das menores médias, com valores de $0,4 \mathrm{e}$ $0,5 \mathrm{~kg} / \mathrm{cm}^{2}$. Segundo Fagundes e Yamanishi (2001), firmeza da polpa e do fruto são características físicas geralmente influenciadas por condições ambientais, cultivar, época de colheita e tratos culturais.

Sólidos solúveis são um dos principais parâmetros de qualidade de frutos de mamão. A exigência para comercialização de mamão para exportação em relação a SS, é que apresente ${ }^{\circ}$ Brix superior a 12 . Um pouco mais de $50 \%$ dos genótipos avaliados obtiveram valores médios de sólidos solúveis acima de $12^{\circ}$ Brix. As linhagens L26 (Solo) e L36 (Formosa), os híbridos H10.26, H10.60 e H60.72 (Solo) e a testemunha Sunrise Solo não diferiram estatisticamente entre si e apresentaram as maiores médias, variando de 12,6 a 13,3 ${ }^{\circ}$ Brix. Seis genótipos (linhagens e híbridos) não apresentaram diferenças significativas, com médias de 12,0 a $12,5^{\circ}$ Brix. As linhagens e híbridos L10, L60, L56, H10.72, H26.72, $\mathrm{H} 33.45, \mathrm{H} 33.56, \mathrm{H} 45.46 \mathrm{e}$ a testemunha Tainung $\mathrm{n}^{\circ} 1$ tiveram médias de 11,0 a $11,9^{\circ}$ Brix e não diferiram estatisticamente. Por outro lado, a linhagem L33 foi o único genótipo que apresentou valor médio inferior a $11,0^{\circ} \mathrm{Brix}$, com média igual a $9,9^{\circ} \mathrm{Brix}$, diferindo dos demais. Marin et al. (2006) corroboram estes resultados, ao observarem variação de 7,85 a 12,65
${ }^{\circ}$ Brix na análise de híbridos de mamoeiro; Oliveira et al. (2010) detectaram ampla variabilidade na análise de germoplasma, encontrando valores de 5,0 a 16,2 ${ }^{\circ}$ Brix, e Dias et al. (2011), avaliando 27 genótipos de mamoeiro, obtiveram médias de 7,25 a 11,53 ${ }^{\circ}$ Brix.

A variação nos teores de sólidos solúveis é bastante influenciada por condições ambientais, época de colheita, estações do ano, estádios de maturação e tratos culturais. Brito Neto et al. (2011) verificaram crescimento linear dos $\mathrm{SS}$, variando de 7 a $14^{\circ}$ Brix, em função da adição das doses de nitrogênio. Souza (2004) observou diferença significativa nos teores de SS entre os estádios de maturação, indicando maior teor de sólidos solúveis no estádio máximo de maturação. Segundo Fonseca (2002), o mamão colhido antes da maturidade fisiológica não amadurece adequadamente, sendo a época de colheita um fator importante e que influencia principalmente na pigmentação do fruto e no teor de sólidos solúveis.

Apesar de serem detectadas diferenças significativas a $1 \%$ de probabilidade entre os genótipos para $\mathrm{pH}$ e $\mathrm{AT}$, não foram observadas grandes variações nos valores, com estimativas de 5,16 a 5,46 e 0,5096 a $0,7970 \%$ de ácido cítrico, respectivamente. Estes dados foram similares aos observados por Fagundes e Yamanishi (2001) para mamão do grupo Solo com $\mathrm{pH}$ igual a 5,55. Miranda et al. (2002) encontraram $\mathrm{pH}$ de 5,3,5,5 e 5,6 em frutos de três cultivares do grupo Solo, e Dias et al. (2011) obtiveram médias entre 5,22 e 5,64. Os resultados obtidos no presente trabalho para AT $(0,5096$ a $0,7970 \%)$ foram superiores aos observados por Fagundes e Yamanishi (2001), variando de 0,04 a $0,16 \%$, por Brito Neto et al. (2011), que encontraram valores médios de 0,0445 a $0,283 \%$ e por Dias et al. (2011), que obtiveram estimativas de 0,05 a $0,14 \%$. 
TABELA 1- Esquema de cruzamento em dialelo completo com 4 linhagens do grupo Solo.

Solo

\begin{tabular}{cc|cccc} 
& & L10 & L26 & L60 & L72 \\
\hline L10 & -- & H10.26 & H10.60 & H10.72 \\
응 & L26 & & -- & H26.60 & H26.72 \\
ஜ & L60 & & & -- & H60.72 \\
& L72 & & & & --
\end{tabular}

TABELA 2- Esquema de cruzamento em dialelo completo com 4 linhagens do grupo Formosa.

Formosa

\begin{tabular}{|c|c|c|c|c|}
\hline & L33 & L36 & L45 & L56 \\
\hline L33 & -- & H33.36 & H33.45 & H33.56 \\
\hline L36 & & -- & H36.45 & H36.56 \\
\hline L45 & & & -- & $\mathrm{H} 45.56$ \\
\hline L56 & & & & - \\
\hline
\end{tabular}

TABELA 3- Análise da variância para caracteres agronômicos e referentes à qualidade de frutos avaliados em genótipos de mamoeiro. Cruz das Almas-BA, 2012/2013.

\begin{tabular}{cccccc}
\hline FV & BLOCO & GENÓTIPO & RESÍDUO & MÉDIA & CV \\
\hline GL & 3 & 21 & 63 & --- & --- \\
\hline Caracteres & \multicolumn{5}{c}{ Quadrados Médios } \\
\hline AP & 726,31 & $829,07^{* *}$ & 204,82 & 150,8 & 9,48 \\
AIPF & 277,95 & $558,55^{* *}$ & 111,96 & 102,3 & 10,34 \\
DC & 3,50 & $0,84^{\text {ns }}$ & 1,11 & 7,80 & 13,50 \\
NFC & 11,29 & $227,36^{* *}$ & 46,13 & 29,30 & 11,44 \\
NFD & 4,84 & $4,96^{* *}$ & 2,58 & 2,36 & 25,02 \\
NNSF & 3,18 & $9,51^{*}$ & 6,45 & 5,61 & 20,54 \\
PROD & 26,29 & $978,15^{* *}$ & 130,84 & 47,50 & 24,07 \\
CF & 0,35 & $35,54^{* *}$ & 1,21 & 19,22 & 5,72 \\
DF & 1,69 & $7,25^{*}$ & 4,13 & 9,94 & 19,55 \\
PF & 11843,47 & $258302,56^{* *}$ & 14262,22 & 901,41 & 13,24 \\
EP & 0,04 & $0,14^{* *}$ & 0,05 & 2,63 & 9,15 \\
DCI & 0,50 & $1,33^{* *}$ & 0,30 & 4,67 & 11,80 \\
FF & 0,33 & $1,54^{* *}$ & 0,50 & 2,37 & 30,02 \\
FP & 0,22 & $0,80^{* *}$ & 0,10 & 0,84 & 37,93 \\
SS & 0,71 & $2,70^{* *}$ & 0,39 & 11,98 & 5,21 \\
pH & 0,0022 & $0,0303^{* *}$ & 0,0045 & 5,26 & 1,28 \\
AT & 0,013 & $0,019^{* *}$ & 0,006 & 0,6720 & 11,91 \\
\hline
\end{tabular}

'AP: altura da planta $(\mathrm{cm})$; AIPF: altura dos primeiros frutos $(\mathrm{cm})$; DC: diâmetro do caule $(\mathrm{cm})$; NFC: número de frutos comerciais; NFD: número de frutos deformados; NNSF: número de nós sem frutos; PROD: produtividade (t.ha- $\left.{ }^{-1}\right)$; CF: comprimento de fruto (cm); DF: diâmetro de fruto (cm); PF: peso de fruto (gramas); EP: espessura da polpa $(\mathrm{cm})$; DCI: diâmetro da cavidade interna $(\mathrm{cm}) ; \mathrm{FF}$ : firmeza do fruto $\left(\mathrm{kg} / \mathrm{cm}^{2}\right)$; FP: firmeza da polpa $\left(\mathrm{kg} / \mathrm{cm}^{2}\right)$; SS: sólidos solúveis ( ${ }^{\circ}$ Brix); $\mathrm{pH}$ e AT: acidez titulável. ** Significativo a $1 \%$ de probabilidade, pelo teste $\mathrm{F}$ e * Significativo a $5 \%$ de probabilidade, pelo teste $\mathrm{F}$. 


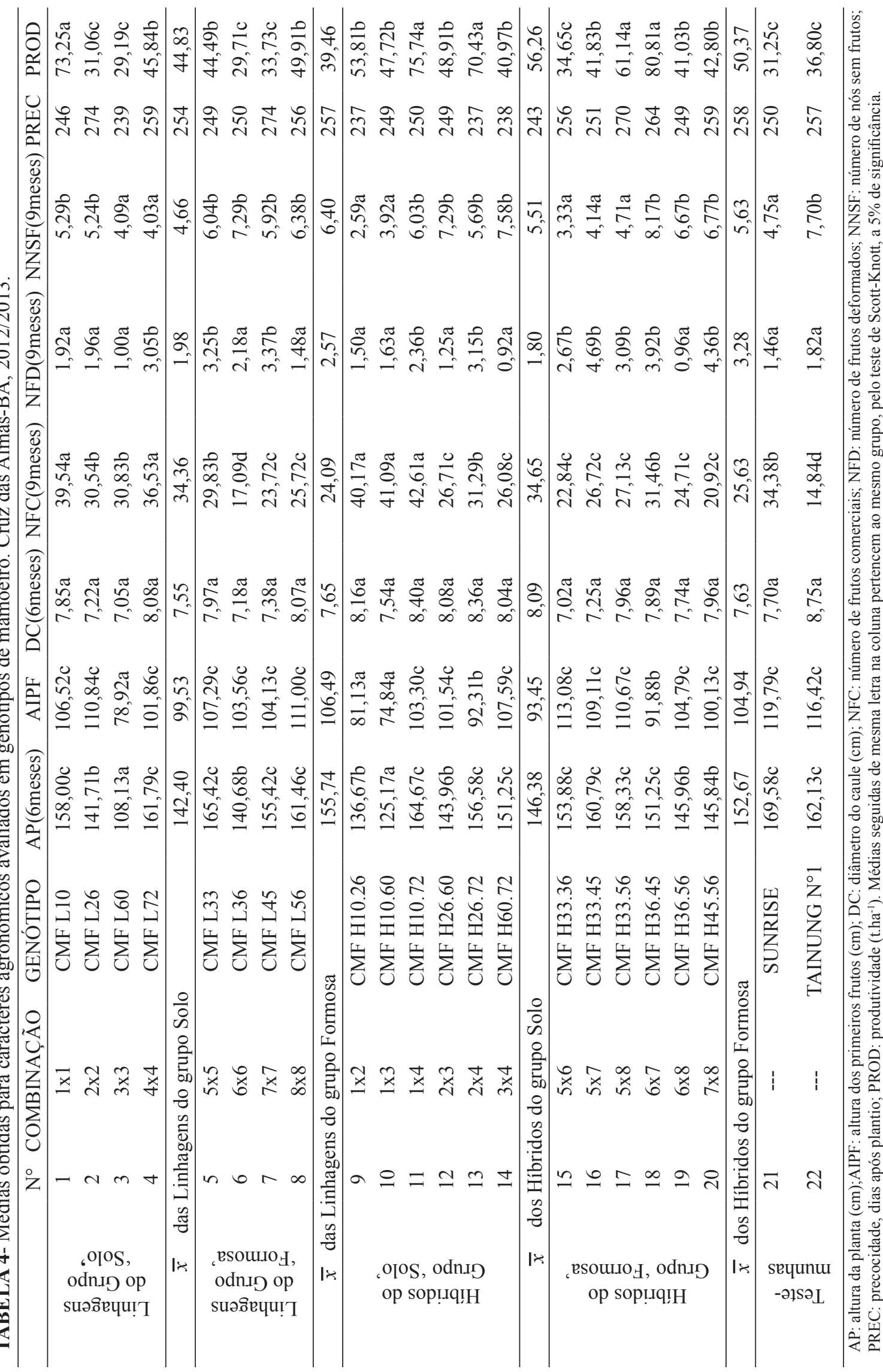




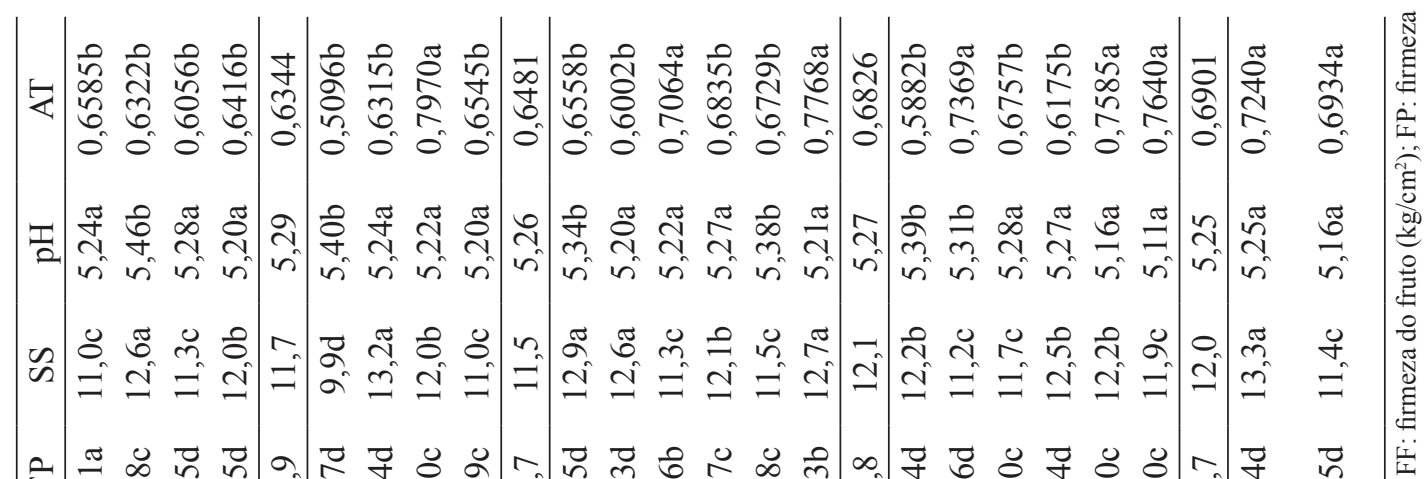

$\stackrel{\text { ì }}{\stackrel{2}{2}}$

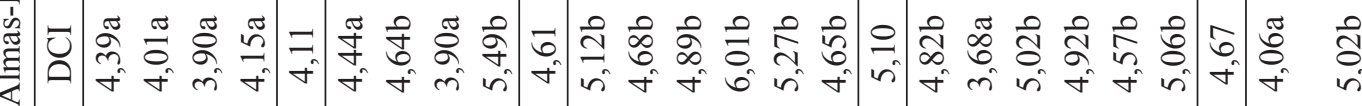

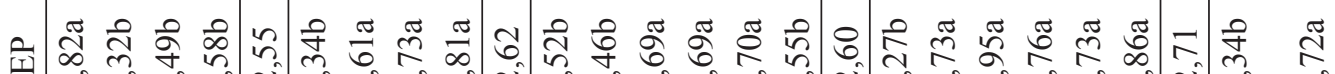

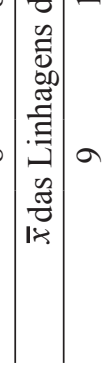




\section{CONCLUSÕES}

Evidenciou-se que a maioria dos caracteres avaliados apresenta grande variabilidade genética, passível de utilização nos processos de seleção de parentais e híbridos para uso per se ou em cruzamentos para síntese de híbridos melhorados, visando ao aumento da competitividade e da sustentabilidade do agronegócio do mamoeiro.

As linhagens L10 e L60 podem ser mais exploradas no programa de melhoramento, visando a desenvolver novos híbridos com características desejáveis para altura da planta, altura dos primeiros frutos, número de frutos comerciais e produtividade.

Todos os híbridos do grupo Solo apresentaram produtividades superiores a 40 t.ha ${ }^{-1}$, média nacional da variedade Sunrise Solo.

Os híbridos H10.26, H10.60 e H10.72, do grupo Solo, mostraram-se promissores por apresentarem menores valores com relação à altura da planta, altura de inserção dos primeiros frutos e maior número de frutos comerciais, produtividade superior à variedade comercial Sunrise Solo e alto teor de sólidos solúveis.

\section{AGRADECIMENTOS}

Ao CNPq, pelo apoio financeiro. À Embrapa Mandioca e Fruticultura, pela infraestrutura para a execução do trabalho.

\section{REFERÊNCIAS}

BADILlO, V. M. Carica L. vs Vasconcella St. Hil. (Caricaceae): com le rehabilitación de este ultimo. Ernstia, Macaray, v.10, n.10, p. 74-79, 2000.

BRITO NETO, J. F.; PEREIRA, W. E.; CAVALCANTI, L. F.; ARAÚJO, R. C.; LACERDA, J. S. Produtividade e qualidade de frutos de mamoeiro 'Sunrise Solo' em função de doses de nitrogênio e boro. Semina: Ciências Agrárias, Londrina, v. 32, n. 1, p. 69-80, jan/mar. 2011.

CRUZ, C. D. Programa Genes: estatística experimental e matrizes. Viçosa: Editora UFV, 2006. v.1, 285 p.

DANTAS, J. L. L.; LIMA, J. F. Seleção e recomendação de variedades de mamoeiro avaliação de linhagens e híbridos. Revista Brasileira de Fruticultura, Jaboticabal, v. 23, n.3, p. 617-621, 2001.
DANTAS, J. L. L.; PINTO, R. M. S.; LIMA, J. L.; FERREIRA, F. R. Catálogo de germoplasma de mamão (Carica papaya L.). Cruz das AlmasBA: Embrapa Mandioca e Fruticultura, 2000. 40p. (Embrapa Mandioca e Fruticultura, Documentos, 94).

DANTAS, J. L. L; OLIVEIRA, E. J. de. Avances en el mejoramiento de papaya. In: CONGRESSO ARGENTINO DE HORTICULTURA, 32.; SIMPÓSIO LATINO AMERICANO DE FRUTICULTURA TROPICAL, 1., 2009, Salta. Anais... Salta: Instituto Nacional de Tecnologia Agropecuária, 2009.

DIAS, N. L. P.; OLIVEIRA, E. J. de; DANTAS, J. L. L. Avaliação de genótipos de mamoeiro com uso de descritores agronômicos e estimação de parâmetros genéticos. Pesquisa Agropecuária Brasileira, Brasília, v. 46, n. 11, p. 1471-1479, 2011.

EMBRAPA. Solos do nordeste. Recife: Embrapa Solos UEP, 2006. Disponível em: $<$ http://www.uep. cnps.embrapa.br/solos $>$. Acesso em: 23 set. 2014.

FAGUNDES, G. R.; YAMANISHI, O. K. Características físicas e químicas de frutos de mamoeiro do grupo 'Solo' comercializados em quatro estabelecimentos de Brasília- DF. Revista Brasileira de Fruticultura, Jaboticabal, v. 23, n.3, p. 345-350, 2001.

FERREIRA, J. P.; SCHMILDT, O.; SCHMILDT, E. R.; PIANTAVINHA, W. C.; CATTANEO, L. F. Correlações entre características morfoagronômicas de acessos de mamoeiro. Enciclopédia Biosfera Centro Científico Conhecer, Goiânia, v. 8, n. 14, p. 247, 2012.

FIORAVANÇO, J. C.; PAIVA, M. C.; CARVALHO, R. I. N.; MANICA, I. Qualidade do mamão 'Solo' comercializado em Porto Alegre, de outubro/91 a junho/92. Revista Ciência Agronômica, Fortaleza, v. 27 , n. $1 / 2$, p. 67-71, 1996.

FONSECA, M. J. de O. Conservação pós-colheita de mamão (Carica papaya L.): análise das cultivares Sunrise Solo e Golden, sob controle de temperatura e de atmosfera modificada. 2002. 177 f. Tese (Doutorado em Produção Vegetal) - Universidade do Norte Fluminense, Campos dos Goytacazes, 2002. 
FRAIFE FILHO, G. A.; DANTAS, J. L. L.; LEITE, J. B. V.; OLIVEIRA, J. R. P. Avaliação de variedades de mamoeiro no extremo sul da Bahia. Magistra, Cruz das Almas, v. 13, n. 1, jan./jun., 2001.

GEPTS, P. Plant genetic resources conservation and utilization: the accomplishments and future of a societal insurance policy. Crop Science, Madison, v. 46, n. 5, p. 2278-2296, 2006.

GRIFFING, B. The concept of general and specific combining ability in relation to diallel crossing systems. Australian Journal of Biological Sciences, East Melbourn, v. 9, p. 463- 493, 1956.

IBGE - Instituto Brasileiro de Geografia e Estatística. Banco de dados agregados. Sistema IBGE de Recuperação Automática - SIDRA. Disponível em: $<$ http://www.ibge.gov.br>. Acesso em: 21 dez. 2012.

IBPGR - International Board for Plant Genetic Resources. Descriptors for papaya. Roma, 1988. $31 \mathrm{p}$.

MARIN, S. L. D.; GOMES, J. A.; ALVES, F. L. Introdução, avaliação e seleção do mamoeiro cv. Improved Sunrise Solo Line 72/12 no Estado do Espírito Santo. Vitória: EMCAPA, 1989. 13 p. (Documentos, 59).

MARIN, S. L. D.; PEREIRA, M. G.; AMARAL JÚNIOR, A. T.; MARTELLETO, L. A. P.; IDE, C. D. Partial diallel to evaluate the combining ability for economically important traits of papaya. Scientia Agricola, Piracicaba, v. 63, p. 540-546, 2006.

MARTINS, D. dos S.; COSTA, A. de F. S. da. A cultura do mamoeiro: tecnologias de produção. Vitória: Incaper, 2003. 497p.

MIRANDA, S. P.; FAGUNDES, G. R.; MACHADO FILHO, J. A.; MORAES, A. V.; LIMA, L. A.; YAMANISHI, O. K. Caracterização física e química de mamões dos grupos Solo e Formosa cultivados em Brasília - DF. In: CONGRESSO BRASILEIRO DE FRUTICULTURA, 17., 2002, Belém. Anais... Belém: Sociedade Brasileira de Fruticultura, 2002. CD-ROM.
OLIVEIRA, E. J.; LIMA, D. S.; MACHADO, M. D.; LUCENA, R. S.; MOTTA, T. B. N.; DANTAS, J. L. Correlações genéticas e análise de trilha para número de frutos comerciais por planta em mamoeiro. Pesquisa Agropecuária Brasileira, Brasília, v.45, p.855-862, 2010.

SILVA, F. F.; PEREIRA, M. G.; RAMOS, H. C. C.; DAMASCENO JÚNIOR, P. C.; PEREIRA, T. N. S.; IDE, C. D. Genotypic correlations of morphoagronomic traits in papaya and implications for genetic breeding. Crop Breeding and Applied Biotechnology, Londrina, v.7, n.2, p. 345-352, 2007.

SILVA, F. F.; PEREIRA, M. G.; RAMOS, H. C. C.; DAMASCENO JÚNIOR, P. C.; PEREIRA, T. N. S.; VIANA, A. P.; HAHER, R. F.; FERREGUETTI, G. A. Estimation of genetic parameters related to morpho-agronomic and fruit quality traits of papaya. Crop Breeding and Applied Biotechnology, Londrina, v. 8, n.1, p. 65-73, 2008.

SILVA, M. M.; BROETTO, S. G.; VALBÃO, S. C.; COSTA, A. F. S.; SILVA, D. M. Características vegetativas e de frutos de mamoeiros obtidos por seleção massal. Semina: Ciências Agrárias, Londrina, v. 31, n. 1, p. 29-38, 2010.

SIMÃO, S. Tratado de fruticultura. Piracicaba: FEALQ, 1998. p. 541-572.

SOUZA, L. M. de. Algumas caracteristicas físicas e químicas de mamões (Carica papaya L.) dos grupos "FORMOSA" (Tainung 01) e "SOLO" (Golden), com e sem mancha fisiológica, colhidos em diferentes estádios de maturação. 2004. 82 f. Dissertação (Mestrado) - Universidade Estadual do Norte Fluminense, Campos dos Goytacazes, 2004.

SOUZA, T. V.; COELHO, E. F.; PAZ, V. P. S.; LEDO, C. A. S. Avaliação física e química de frutos de mamoeiro 'Tainung $\mathrm{n}^{\circ} 1$ ', fertirrigado com diferentes combinações de fontes nitrogenadas. Revista Brasileira Ciências Agrárias. Recife, v. 4, n. 2, p.179-184, 2009.

YAMANISHI, O. K.; MELLO, R. M.; MARTINS, V. A.; LIMA, L. A.; FAGUNDES, G. R. Comportamento do mamoeiro Sekati nas condições do oeste da Bahia. Revista Brasileira de Fruticultura, Jaboticabal, v. 28, n. 1, p. 79- 82, 2006. 